\title{
The Major Outer Membrane Protein of Fusobacterium nucleatum (FomA) Folds and Inserts into Lipid Bilayers via Parallel Folding Pathways
}

\author{
Cosmin L. Pocanschi ${ }^{1}$, Hans-Jürgen ApelI ${ }^{1}$, Pål PuntervolI ${ }^{2}$, Bente Høgh ${ }^{2}$ \\ Harald B. Jensen ${ }^{2}$, Wolfram Welte ${ }^{1}$ and Jörg H. Kleinschmidt ${ }^{1 *}$
}

${ }^{1}$ Fachbereich Biologie

Universität Konstanz, D-78457

Konstanz, Germany

${ }^{2}$ Department of Molecular Biology, University of Bergen N-5020 Bergen, Norway

\begin{abstract}
Membrane protein insertion and folding was studied for the major outer membrane protein of Fusobacterium nucleatum (FomA), which is a voltagedependent general diffusion porin. The transmembrane domain of FomA forms a $\beta$-barrel that is predicted to consist of $14 \beta$-strands. Here, unfolded FomA is shown to insert and fold spontaneously and quantitatively into phospholipid bilayers upon dilution of the denaturant urea, which was shown previously only for outer membrane protein A (OmpA) of Escherichia coli. Folding of FomA is demonstrated by circular dichroism and fluorescence spectroscopy, by SDS-polyacrylamide gel electrophoresis, and by single-channel recordings. Refolded FomA had a single-channel conductance of $1.1 \mathrm{nS}$ at $1 \mathrm{M} \mathrm{KCl}$, in agreement with the conductance of FomA isolated from membranes in native form. In contrast to OmpA, which forms a smaller eight-stranded $\beta$-barrel domain, folding kinetics of the larger FomA were slower and provided evidence for parallel folding pathways of FomA into lipid bilayers. Two pathways were observed independent of membrane thickness with two different lipid bilayers, which were either composed of dicapryl phosphatidylcholine or dioleoyl phosphatidylcholine. This is the first observation of parallel membrane insertion and folding pathways of a $\beta$-barrel membrane protein from an unfolded state in urea into lipid bilayers. The kinetics of both folding pathways depended on the chain length of the lipid and on temperature with estimated activation energies of $19 \mathrm{~kJ} / \mathrm{mol}$ (dicapryl phosphatidylcholine) and $70 \mathrm{~kJ} / \mathrm{mol}$ (dioleoyl phosphatidylcholine) for the faster pathways.
\end{abstract}

Keywords: folding kinetics; membrane protein folding; insertion; outer membrane protein; $\beta$-barrel membrane protein

\section{Introduction}

Abbreviations used: $\mathrm{BR}$, bacteriorhodopsin; $\mathrm{CD}$, circular dichroism; di $\mathrm{C}_{10: 0} \mathrm{PC}, 1$,2-dicapryl-sn-glycero-3phosphocholine; $d i \mathrm{C}_{18: 1} \mathrm{PC}, 1$,2-dioleoyl-sn-glycero-3phosphocholine; diPhPC, 1,2-diphytanoyl-sn-glycero-3phosphocholine; FomA, major outer membrane protein A of Fusobacterium nucleatum; IMP, integral membrane protein; KTSE, kinetics of tertiary structure formation determined by electrophoresis; LDAO, $N$-lauryl- $N, N$ dimethylammonium- $N$-oxide; LUVs, large unilamellar vesicles; lyso $\mathrm{C}_{10: 0} \mathrm{PC}$, 1-capryl-2-hydroxy-sn-glycero-3phosphocholine; OMP, outer membrane protein; OmpA, outer membrane protein A from Escherichia coli; SUVs, small unilamellar vesicles.

E-mail address of the corresponding author: joerg.helmut.kleinschmidt@uni-konstanz.de
A central question for the assembly of biological membranes is how integral membrane proteins (IMPs) insert and fold into membranes, which form the interface of the different functional compartments of living cells. Since IMPs are hydrophobic and usually insoluble in water, biophysical investigations on the mechanisms of membrane insertion and folding of IMPs are experimentally challenging and until today, insertion and folding have been studied for only a few IMPs. Currently, two different types of IMPs can be distinguished by the secondary structure of their transmembrane domains: $\beta$-barrel membrane proteins and $\alpha$-helix bundle membrane proteins. Transmembrane 
$\beta$-barrels have been reported for the outer membranes of Gram-negative bacteria and certain cell organelles, such as mitochondria. They serve a variety of different functions, for example they can be unspecific or specific porins, active transporters, proteases, or lipases. ${ }^{1,2}$ Genetic evidence suggests that periplasmic chaperones such as $\mathrm{Skp}^{3}$ or SurA ${ }^{4}$ and also protein complexes in the outer membrane, containing the protein YaeT in Escherichia coli ${ }^{5}$ (Omp85 in Neisseria meningitides ${ }^{6}$ ) facilitate membrane integration of outer membrane proteins (OMPs). However, previous studies also demonstrated that OMPs refold spontaneously into detergent micelles or lipid bilayers in the absence of proteinaceous folding machinery. ${ }^{7-16}$

Folding of OMPs of bacteria into detergent micelles has been studied with the monomeric outer membrane proteins $A(\mathrm{OmpA})^{16,17}$ and $\mathrm{G}$ $(\mathrm{OmpG}){ }^{11}$ with the trimeric PhoE, ${ }^{18}$ and with the monomeric E.coli auto-transporter adhesin involved in diffuse adherence (AIDA). ${ }^{19}$ Folding of OMPs into detergent micelles is often successful and fast because of the physical properties of the micelles, ${ }^{8,16}$ which are small and consist of relatively few amphiphiles that are in rapid exchange with their monomers in solution.

In contrast to micelles, bilayers contain a much larger number of molecules and they are tightly packed. Lipid bilayers form the backbone of biological membranes and are widely used in model systems to study assembly, structure, dynamics, and function of biomembranes. Until now the outer membrane protein A of E. coli (OmpA) was the only OMP, for which direct folding into lipid bilayers from a urea-denatured state was studied with folding yields close to $100 \%{ }^{13,15}$ Therefore, OmpA (325 residues, $M_{\mathrm{r}} 35 \mathrm{kDa}$ ) has been an extensively studied model for the basic mechanistic principles of folding of $\beta$-barrel mem-

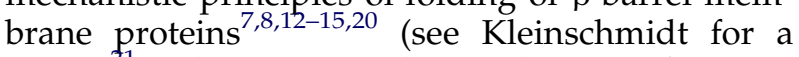
review $^{21}$ ). The transmembrane domain of OmpA is an eight-stranded $\beta$-barrel composed of 171 amino acid residues. ${ }^{22,23}$

Here we investigated membrane protein folding into lipid bilayers for a second OMP that has a much larger transmembrane domain to examine differences and similarities in comparison to OmpA. We chose FomA, the major porin of Fusobacterium nucleatum for this study. FomA is involved in the binding between fusobacteria and Streptococcus sanguis on the tooth-surface and to Porphyromonas gingivalis in the periodontal pockets. ${ }^{24}$ The structure of FomA has not yet been solved, but recent circular dichroism (CD) spectroscopy and topology prediction suggested a 14 -stranded transmembrane $\beta$-barrel. ${ }^{25}$ FomA forms voltage-dependent diffusion channels, ${ }^{25,26}$ which have a conductivity of $\sim 1.2 \mathrm{nS}$, i.e. much greater than $\sim 250-320 \mathrm{pS}$ reported for the large open state of OmpA, ${ }^{27}$ which is in agreement with a larger size of the transmembrane domain of FomA.

We have studied insertion and folding of FomA (40.3 $\mathrm{kDa}, 352$ residues), since like OmpA, it is observed as a monomer when analyzed by SDSPAGE without heat-denaturing the samples prior to electrophoresis. $^{26}$ For OmpA folding into thin bilayers of short-chain phospholipids, a singlestep folding mechanism has been described that followed a simple second-order rate law. ${ }^{15}$ The tools of this previous study were an electrophoretic mobility assay, indicating the presence of compact, natively folded $\mathrm{OmpA},{ }^{28} \mathrm{CD}$ spectroscopy indicating the formation of native secondary structure, and fluorescence spectroscopy showing insertion into the lipid bilayer. Electrophoresis and CD spectroscopy demonstrated that the formation of secondary and tertiary structure in OmpA is synchronized and has the same second-order rate constant that decreases with increasing bilayer thickness. ${ }^{15}$ Here, we first investigated whether urea-denatured FomA folds into either detergent micelles or model membranes of phospholipids and whether folding is quantitative. To investigate the folding rates and basic principles of the folding mechanism of a larger transmembrane $\beta$-barrel, we examined the folding kinetics of FomA into lipid bilayers and compared it to previous studies on OmpA. Similar to OmpA, unfolded FomA could be refolded into lipid bilayers. However, the kinetics of FomA folding was more complex than the kinetics of OmpA folding and our data provided the first evidence for parallel folding pathways of $\beta$-barrel membrane proteins into lipid bilayers. In our kinetic analysis, we estimated the rate constants and the required activation energies for each of the two observed parallel folding processes.

\section{Results}

\section{Unfolded FomA inserts and folds into lipid bilayers and detergent micelles}

Native and denatured forms of many OMPs migrate at two different apparent molecular masses in sodium dodecyl sulfate-polyacrylamide gel electrophoresis (SDS-PAGE), if the samples are not boiled prior to electrophoresis (cold SDS-PAGE). Native OMPs usually migrate faster than unfolded OMPs, which is a consequence of the compactness of the very stable $\beta$-barrel structures. This property was first described for OmpA of E. coli, ${ }^{28}$ and later for other OMPs such as OmpG, ${ }^{11}$ FhuA $^{29}$ and FomA. ${ }^{25,26}$ On SDS-polyacrylamide gels, FomA migrates at $37 \mathrm{kDa}$ in native form when isolated from membranes and at $40 \mathrm{kDa}$ when denatured either by heat or by urea. ${ }^{25}$

To first investigate the conditions required for the folding of FomA, we examined the electrophoretic mobility of FomA in unfolded form in urea, after denaturant dilution in aqueous solution, and also after incubation with detergent micelles or lipid bilayers, which in previous studies induced folding of OmpA. ${ }^{76,17}$ We expected that successful folding of FomA should change the electrophoretic 
mobility from $40 \mathrm{kDa}$ of the unfolded form to $37 \mathrm{kDa}$ of the native form as seen in previous studies on OmpA, which migrated at $35 \mathrm{kDa}$ in unfolded form and at $30 \mathrm{kDa}$ in refolded, functionally active form. $7,8,13,15-17,20,27,28$

Unfolded FomA in $10 \mathrm{M}$ urea migrated at $40 \mathrm{kDa}$ in cold SDS-PAGE (Figure 1(a), lane 1). When we diluted solutions of urea unfolded FomA either with solutions of LDAO-detergent or lysocapryl phosphatidylcholine, thereby strongly decreasing the denaturant concentration, and then incubated these samples at $40{ }^{\circ} \mathrm{C}$ for $24 \mathrm{~h}$, FomA migrated at an apparent molecular mass of $37 \mathrm{kDa}$ (Figure 1(a), lanes 2 and 3), indicating that it had refolded. While the presence of preformed micelles induced folding of FomA, the dilution of urea in the absence of detergent did not change the electrophoretic mobility at $40 \mathrm{kDa}$ of this aqueous form of FomA, suggesting that FomA does not fold in the absence of micelles (Figure 1(b), lane 3), which is in agreement with previous studies on OmpA. ${ }^{16}$

(a)

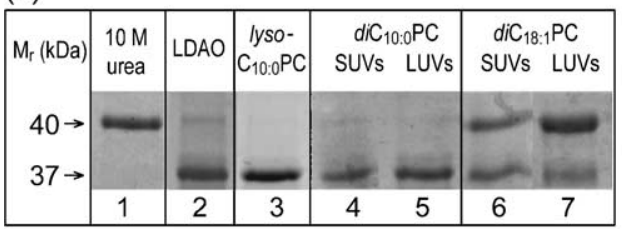

(b)

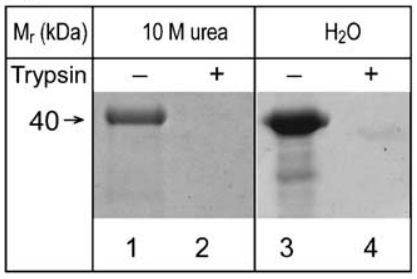

\begin{tabular}{|c|c|c|c|c|c|c|c|}
\hline \multirow{2}{*}{\begin{tabular}{|l}
$\mathrm{Mr}_{\mathrm{r}}(\mathrm{kDa})$ \\
Trypsin
\end{tabular}} & $d i C_{10: 0} P C$ SUVs & \multicolumn{2}{|c|}{ dic ${ }_{10: 0} \mathrm{PC}$ LUVs } & \multicolumn{2}{|c|}{$d_{i C_{18: 1} P C}$ SUVs } & \multicolumn{2}{|c|}{$\mathrm{diC}_{18: 1} \mathrm{PC}$ LUVs } \\
\hline & - & - & + & - & + & - & + \\
\hline $\begin{array}{l}37 \rightarrow \\
34 \rightarrow\end{array}$ & $\Leftrightarrow$ & $\rightarrow$ & 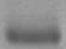 & $=$ & $\mathrm{ax}$ & has & \\
\hline & 5 & 7 & 8 & 9 & 10 & 11 & 12 \\
\hline
\end{tabular}

Figure 1. Insertion and folding of FomA into LDAO detergent micelles and into lipid bilayers of $d i \mathrm{C}_{10: 0} \mathrm{PC}$ and $d_{i C_{18: 1}} \mathrm{PC}$ analyzed by SDS-PAGE. (a) Migration of FomA in denatured form in $10 \mathrm{M}$ urea (lane 1) and after incubation at $40{ }^{\circ} \mathrm{C}$ for $24 \mathrm{~h}$ with LDAO micelles (lane 2), lysocapryl phosphatidylcholine micelles (lane 3), $\mathrm{diC}_{10: 0} \mathrm{PC}$ bilayers of small (lane 4) or large (lane 5) vesicles, and $d i \mathrm{C}_{18: 1} \mathrm{PC}$ bilayers of small (lane 6) or large (lane 7) vesicles. (b) Samples before $(-)$ and after $(+)$ proteolysis with trypsin. Urea-denatured FomA (lane 1) and aqueous FomA after denaturant dilution (lane 3) were completely cleaved (lanes 2 and 4 ) in the absence of detergent or lipid. In contrast, proteolysis of FomA refolded in micelles or bilayers and migrating at $37 \mathrm{kDa}$ (lanes $5,7,9,11$ ) resulted in a $34 \mathrm{kDa}$ fragment (lanes 6, 8 , $10,12)$, consistent with trypsin digestion experiments on natively isolated FomA in membranes. ${ }^{25}$
We next tested whether FomA can also fold into bilayers of phospholipids and whether insertion and folding depends on lipid properties or on the size of the lipid vesicles. With preformed lipid bilayers of dicapryl phosphatidylcholine $\left(\right.$ diC $\left._{10: 0} \mathrm{PC}\right)$, the unfolded $40 \mathrm{kDa}$ form of FomA was quantitatively converted to the folded $37 \mathrm{kDa}$ form (Figure 1(a), lanes 4 and 5), independent of the size of the vesicles (small unilamellar vesicles, SUVs, prepared by ultrasonication or large unilamellar vesicles, LUVs, prepared by extrusion). In contrast, only $\sim 40-50 \%$ of the folded $37 \mathrm{kDa}$ form of FomA were formed with SUVs of dioleoyl phosphatidylcholine $\left(d_{i C_{18: 1}} \mathrm{PC}\right.$; Figure $1(\mathrm{a})$, lane 6 ) and even lower amounts $(\sim 10 \%)$ were observed with LUVs of $d i C_{18: 1} \mathrm{PC}$ (Figure 1(a), lane 7) under otherwise identical conditions. This last experiment indicated that formation of the folded form depended on both, the chain length of the phospholipid and the size of the lipid vesicles, similar to previous observations on the membrane insertion and folding of OmpA. 13,15,21

To determine whether the refolded $37 \mathrm{kDa}$ form of FomA had inserted into lipid bilayers or detergent micelles, we performed digestion experiments with trypsin, because we expected that micelle- or membrane-inserted parts of the polypeptide chain of FomA would be protected against degradation as observed previously for FomA isolated in native form from cell envelopes. ${ }^{25}$ Figure 1(b) shows that both, denatured (lane 1) and water-collapsed (lane 3) FomA were completely digested by trypsin (lanes 2 and 4), since no band could be observed on SDS-PAGE after $2 \mathrm{~h}$ of incubation of FomA with trypsin at $37^{\circ} \mathrm{C}$. In detergent micelles (data not shown) and lipid bilayers (Figure 1(b), lanes 5 to 12), most of the polypeptide chain of FomA was protected against trypsin digestion, which led to a $34 \mathrm{kDa}$ fragment similar as in previous experiments with FomA isolated in native form in membranes. ${ }^{25}$ The same fragment was obtained, independent of the composition and size of the lipid vesicles (Figure 1(b), lanes 6,8 , and 10), although with LUVs of $d i C_{18: 1} P C$, the bilayer protected fragment of FomA could not be detected possibly because of lower yields of the $37 \mathrm{kDa}$ form in refolding experiments and because of dilution of the solutions upon addition of trypsin and trypsin inhibitor (Figure 1(b), lane 12).

\section{Fluorescence spectroscopy indicates FomA insertion into lipid bilayers}

In IMPs, tryptophan and other aromatic residues typically are found in girdles located close to the membrane-water interface in the hydrophobic core of the lipid bilayer. ${ }^{30,31}$ Therefore, we expected an average location in the membrane-water interface also for the eight fluorescent tryptophan residues of refolded FomA, which should lead to a blue-shift of the maximum of the fluorescence spectrum and to an intensity increase compared to the fluorescence properties of unfolded or aqueous FomA. 

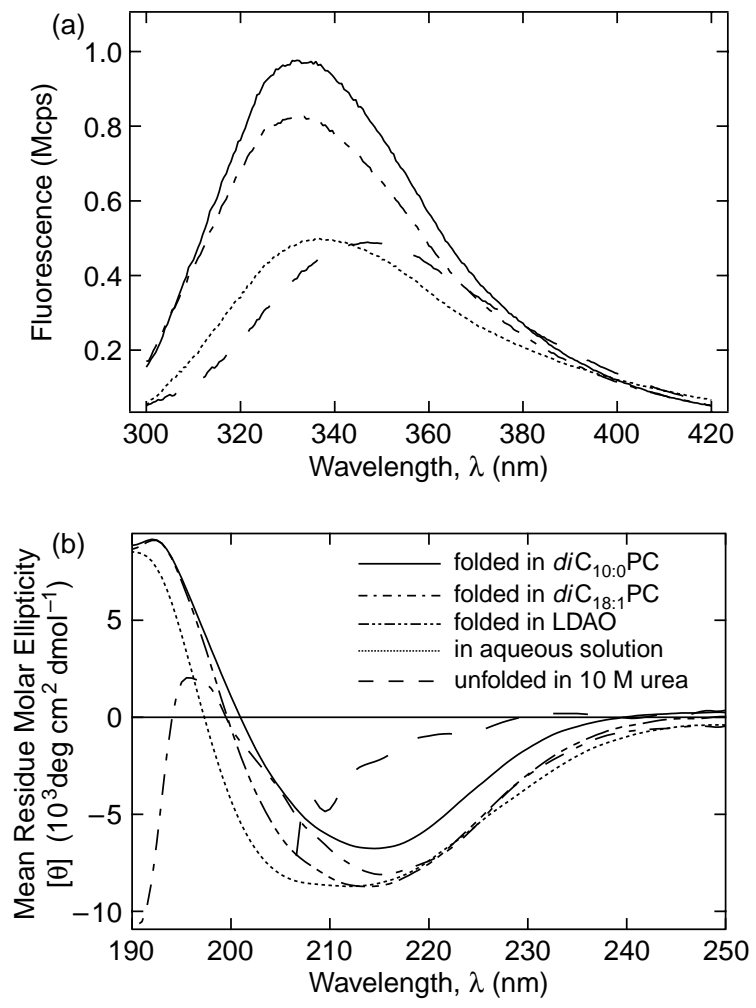

Figure 2. (a) Fluorescence spectra of $0.7 \mu \mathrm{M}$ FomA and (b) circular dichroism spectra of $14 \mu \mathrm{M}$ FomA, in unfolded form in $10 \mathrm{M}$ urea (--), in aqueous solution after urea removal by dialysis $(\cdots)$, and after formation of the refolded, $37 \mathrm{kDa}$ form either with detergent micelles of $\operatorname{LDAO}(-\cdots-\cdot)$, with small vesicles of $d i \mathrm{C}_{10: 0} \mathrm{PC}(-)$, or with small vesicles of $d_{i C_{18: 1}} \mathrm{PC}(-\cdot-\cdot)$ and subsequent urea removal by dialysis. Background spectra without FomA were subtracted. All spectra were recorded at room temperature in $10 \mathrm{mM}$ sodium borate (pH 10.0), 2 mM EDTA.

Fluorescence spectra of urea-unfolded FomA (--) had an emission maximum at $\lambda_{\max }(\mathrm{U})=347 \mathrm{~nm}$ (Figure 2(a)). After urea dilution $(\cdots)$, the wavelength of the intensity maximum of FomA in aqueous solution in the absence of detergent or lipid was shifted to $\lambda_{\max }(A)=337 \mathrm{~nm}$, while the fluorescence intensity was similar to the urea-unfolded FomA. Spectra of the folded $37 \mathrm{kDa}$ form of Fom $\mathrm{A}$ in lipid bilayers of $d i \mathrm{C}_{10: 0} \mathrm{PC}(-)$ or alternatively, of $d i \mathrm{C}_{18: 1} \mathrm{PC}(-\cdot-\cdot)$ were characteri- zed by fluorescence emission maxima at $\lambda_{\max }(\mathrm{F})=$ $332 \mathrm{~nm}$ and by an almost two times larger intensity compared to the fluorescence of the urea-unfolded and aqueous forms of FomA at the same concentration. These results indicated that the Trp residues of folded FomA were located predominantly in more hydrophobic environment after refolding into lipid bilayers.

\section{$\beta$-Sheet secondary structure of refolded FomA}

To examine the secondary structure of refolded FomA in micelles or membranes (migrating at $37 \mathrm{kDa}$ in cold SDS-PAGE) and also in unfolded form in urea or in aqueous solution after urea dilution in the absence of lipid or detergent (migrating at $40 \mathrm{kDa}$ in cold SDS-PAGE), we recorded $C D$ spectra (Figure 2(b)). The spectrum of FomA in urea $(--)$ had relatively small mean residue molar ellipticities $([\theta])$ between $215 \mathrm{~nm}$ and $225 \mathrm{~nm}$, indicating that FomA had mostly random coil secondary structure. When the denaturant urea was diluted, FomA developed secondary structure in aqueous solution even in the absence of detergent or lipid bilayers $(\cdots)$ and analysis of the CD spectrum with several algorithms indicated about $25 \% \quad \beta$-strand, $23.7 \% \quad \beta$-turn, and $20 \% \alpha$-helix secondary structure in this form of FomA (Table 1). The CD spectra of the refolded $37 \mathrm{kDa}$ form of FomA in $\mathrm{LDAO}, d i \mathrm{C}_{10: 0} \mathrm{PC}$ and $d i \mathrm{C}_{18: 1} \mathrm{PC}$ (Figure 2(b)) were characterized by high contents of $\beta$-strand (42-43\%) and $\beta$-turn $(21.5 \%)$ secondary structure, independent of the lipid or detergent used for refolding (Table 1).

The CD spectra were normalized to the concentration of FomA and spectra of the compact $37 \mathrm{kDa}$ form of FomA were very similar to the CD spectra of FomA isolated in native form from membranes. ${ }^{25}$ High content of $\beta$-sheet secondary structure was obtained for the refolded $37 \mathrm{kDa}$ form that was largely protected by the micelle or bilayer environment against proteolysis by trypsin. Cleavage with trypsin led to the same $34 \mathrm{kDa}$ fragment independent of the detergent or lipid used for folding and similar to natively isolated FomA. Since single $\beta$-strands are not stable and cannot cross the hydrophobic region of a micelle or bilayer, refolded FomA therefore formed the same $\beta$-barrel structure, independent of the detergent or lipid.

Table 1. Analyses of the CD spectra of FomA shown in Figure 2(b) ${ }^{\mathrm{a}}$

\begin{tabular}{|c|c|c|c|c|c|}
\hline Sample & Algorithm & $\alpha$-Helix (\%) & $\beta$-Strand (\%) & $\beta$-Turn (\%) & Random coil (\%) \\
\hline Fom $\mathrm{A}$ refolded in $\mathrm{diC}_{10: 0} \mathrm{PC}$ & CONTIN $^{\mathrm{a}, \mathrm{b}}$ & 4.4 & 42.5 & 21.4 & 31.8 \\
\hline FomA refolded in ${ }^{2} \mathrm{C}_{18: 1} \mathrm{PC}$ & CONTIN & 3.6 & 42.8 & 21.6 & 32 \\
\hline FomA refolded in LDAO & CONTIN & 4.2 & 42.4 & 21.6 & 31.8 \\
\hline Aqueous & CONTIN $^{\mathrm{a}}$ & 17.8 & 26.8 & 24.8 & 30.6 \\
\hline \multirow[t]{3}{*}{ Form } & CDSSTR & 16 & 27 & 24 & 33 \\
\hline & SELCON3 & 26.4 & 21.5 & 22.2 & 30.6 \\
\hline & Average & 20 & 25 & 23.7 & 31 \\
\hline
\end{tabular}

Only the CONTIN algorithm yielded the composition of secondary structure for our spectra of refolded FomA. Analysis was performed using DICHROWEB. ${ }^{63}$

a Spectra were analyzed with the algorithms CONTIN, ${ }^{55,56}$ SELCON3, ${ }^{57} \mathrm{CDSSTR}^{58,59}$ 


\section{Refolded FomA is functionally active}

To verify functional activity of refolded FomA we recorded the channel conductance across black lipid films of diPhPC. FomA refolded in LDAO and migrating at $37 \mathrm{kDa}$ on SDS-PAGE formed ion channels when applied to these diPhPC films. Stepwise increases of the current across the diPhPC membrane were observed (Figure 3(a), trace 3). The conductance of a single channel at a salt concentration of $1 \mathrm{M} \mathrm{KCl}$ was in the range of $0.1-2.1 \mathrm{nS}$ with an average of $1.1 \mathrm{nS}$ for a total of 93 singlechannel events (Figure 3(b)). The average conductance was similar to the previously observed average conductance of FomA isolated from membranes in native form, ${ }^{26}$ confirming successful
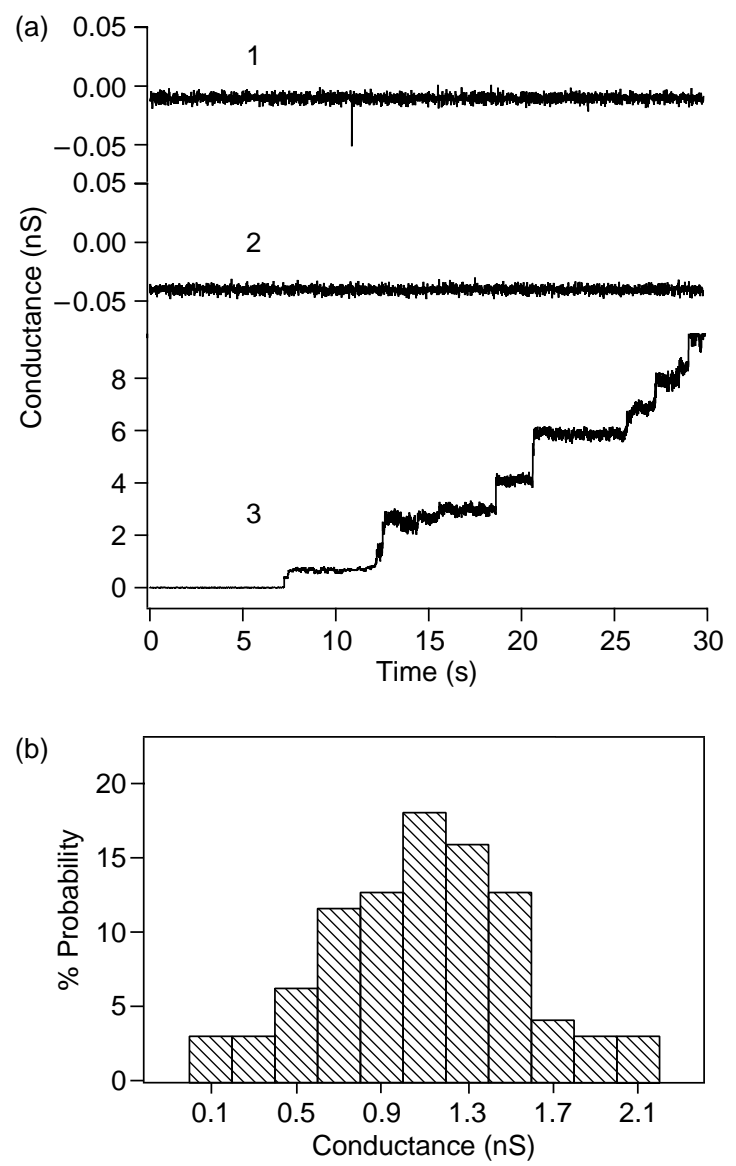

Figure 3. Single channel recordings demonstrate functional activity of refolded FomA. (a) Conductance across black lipid bilayers of diPhPC, after addition of denatured FomA (trace 1), of LDAO detergent in the absence of FomA (trace 2), and after addition of FomA refolded at a molar LDAO/FomA ratio of 800 (trace 3). Both, cis and trans compartments of the Teflon chamber were filled with Mes buffer (10 mM Mes, pH 6.0) containing $1 \mathrm{M} \mathrm{KCl}$. The FomA concentration was $240 \mathrm{pM}$. (b) Histogram of the conductance distribution of single channel recordings. A total of 93 channel events were recorded at room temperature. The conductance of refolded FomA in black lipid films of diPhPC at $1 \mathrm{M}$ $\mathrm{KCl}$ was in the range $0.1-2.1 \mathrm{nS}$ with a maximum probability for a conductance of $1.1 \mathrm{nS}$. refolding of FomA. Addition of the aqueous $40 \mathrm{kDa}$ form of FomA in the absence of LDAO to the diPhPC film did not result in any channel formation (Figure 3(a), trace 1). Similarly, no transmembrane conductance was observed when LDAO detergent (in the absence of FomA) was added to the diPhPC film (Figure 3(a), trace 2). These results demonstrated that our refolding attempts were successful and that the $37 \mathrm{kDa}$ refolded form detected by SDSPAGE is identical to properly folded, functionally active FomA, which is a transmembrane porin. This is in concordance with numerous previous studies on OmpA where the appearance of the $30 \mathrm{kDa}$ refolded form of OmpA indicated that native OmpA structure was formed. $7,8,16,17,22,23,27,32-34$

\section{Kinetics of insertion and folding of FomA into lipid bilayers depend on temperature}

To investigate the mechanism of insertion and folding of FomA, we performed kinetic experiments with phospholipid bilayers (SUVs) of either $\mathrm{diC}_{10: 0} \mathrm{PC}^{15}$ or $\mathrm{diC}_{18: 1} \mathrm{PC}^{13}$ as target membranes. Folding kinetics were obtained by monitoring the increase of the fraction of folded FomA migrating at $37 \mathrm{kDa}$ on SDS-polyacrylamide gels as a function of incubation time. This method, kinetics of tertiary structure formation by electrophoresis (KTSE; see Materials and Methods) has been very useful in previous studies on the folding of other OMPs, such as OmpA $8,13,15,20$ into lipid bilayers and OmpG into detergent micelles ${ }^{11}$ (see Kleinschmidt for a review ${ }^{21}$ ). Figure 4(a) shows the SDS-polyacrylamide gels for the time-courses of FomA folding into di $\mathrm{C}_{10: 0} \mathrm{PC}$ at different temperatures between $10^{\circ} \mathrm{C}$ and $50{ }^{\circ} \mathrm{C}$. Folding of FomA was slow and had to be monitored over a time-course of $24 \mathrm{~h}$ (1440 min). At $10{ }^{\circ} \mathrm{C}$, only about $50 \%$ of FomA folded within $24 \mathrm{~h}$ compared to $50 \%$ folding after $10 \mathrm{~min}$ at $50{ }^{\circ} \mathrm{C}$. This observation demonstrated the strong temperature dependence of FomA folding. The change from $10{ }^{\circ} \mathrm{C}$ to $20^{\circ} \mathrm{C}$ had the largest effect on FomA folding kinetics.

When insertion and folding of FomA into di $_{18: 1} \mathrm{PC}$ was monitored (Figure $4(\mathrm{~b})$ ), formation of the folded $37 \mathrm{kDa}$ form of FomA took much longer and $50 \%$ folding were obtained only after $24 \mathrm{~h}$ at temperatures above $40{ }^{\circ} \mathrm{C}$. Again, FomA insertion and folding was slower at lower temperatures and almost no folding was observed at $10^{\circ} \mathrm{C}$.

\section{Kinetics of FomA folding are composed of at least two folding phases}

The gels of Figure 4 were analyzed by densitometry to determine the fractions of folded FomA as a function of time at each temperature. Figure 5 shows these kinetics of FomA folding for both, $d i C_{10: 0} \mathrm{PC}$ (Figure $5(\mathrm{a})$ ) and $d i \mathrm{C}_{18: 1} \mathrm{PC}$ (Figure 5(b)).

To determine the rate constants and halftimes of folding, we fitted different kinetic models to these data. In previous work, ${ }^{15}$ the folding kinetics of 
(a)

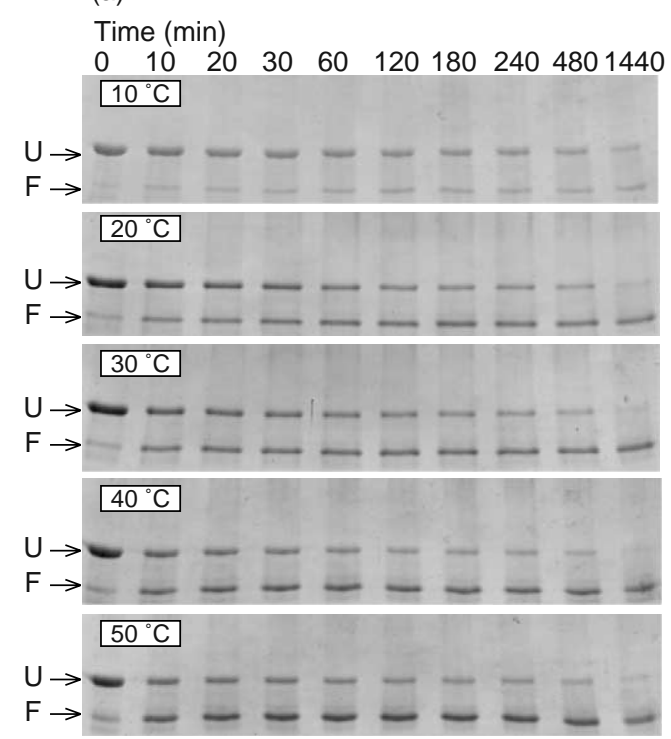

(b)
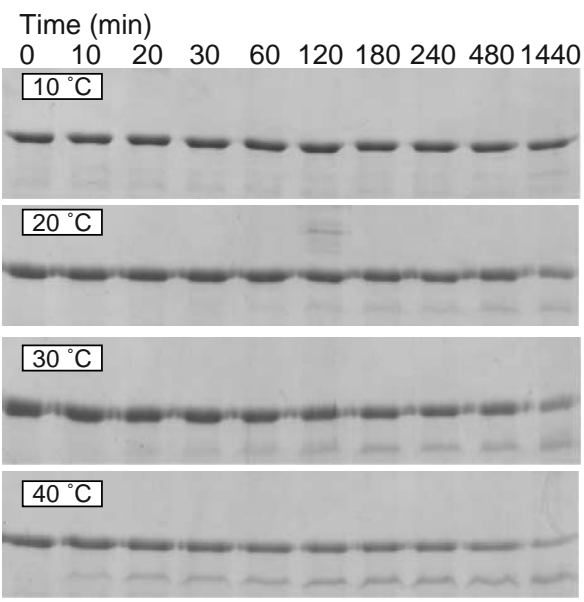

$50^{\circ} \mathrm{C}$

Figure 4. FomA folding kinetics into lipid bilayers depends on temperature and on the chain-length of the lipid. Folding kinetics was monitored over a total time of $24 \mathrm{~h}$ and analyzed by appearance of the $37 \mathrm{kDa}$ folded form $(\mathrm{F})$ at the expense of the unfolded $40 \mathrm{kDa}$ form (U) of FomA on SDS-polyacrylamide gels. For each gel, the fraction of folded FomA was determined by densitometry from the unfolded and folded FomA bands in each lane at 0, 10, 20,30 60, 120, 180, 240, 480, and $1440 \mathrm{~min}$ after initiation of folding. The time-courses were determined for FomA folding into lipid bilayers of $\operatorname{diC}_{10: 0} \mathrm{PC}(\mathrm{a})$ or of $d i \mathrm{C}_{18: 1} \mathrm{PC}(\mathrm{b})$ at temperatures of $10,20,30,40$, and $50{ }^{\circ} \mathrm{C}$. The FomA concentration was $7 \mu \mathrm{M}$ and the molar lipid/FomA ratio was 1000 in $10 \mathrm{mM}$ borate buffer (pH 10, containing 2 mM EDTA).

OmpA into lipid bilayers of either $d i \mathrm{C}_{10: 0} \mathrm{PC}$, $d i \mathrm{C}_{11: 0} \mathrm{PC}$, or $d i \mathrm{C}_{12: 0} \mathrm{PC}$ were also analyzed by densitometry on polyacrylamide gels. These previous kinetic data were very well fitted by a singlestep second-order kinetics, i.e. appearance of the folded form was described by:

$$
\left[P_{\mathrm{F}}\right](t)=\frac{\left[P_{\mathrm{U}}\right]_{0}[L]_{0} \cdot\left(\exp \left\{\left(\left[P_{\mathrm{U}}\right]_{0}-[L]_{0}\right) \cdot k_{2 . \text { ord }} \cdot t\right\}-1\right)}{\left[P_{\mathrm{U}}\right]_{0} \cdot \exp \left\{\left(\left[P_{\mathrm{U}}\right]_{0}-[L]_{0}\right) \cdot k_{2 . \text { ord }} \cdot t\right\}-[L]_{0}}
$$

where $\left[P_{\mathrm{F}}\right](t)$ is the concentration of folded protein at time $t, K_{2 . \text { ord }}$ is the second-order rate constant, $\left[P_{\mathrm{U}}\right]_{0}$ and $[L]_{0}$ are the initial concentrations of unfolded protein and the lipid. ${ }^{15}$ At larger lipid concentrations $(L / P>\sim 100 \mathrm{~mol} / \mathrm{mol})$, fits by a single-step pseudofirst-order kinetics, i.e. simple mono-exponential kinetics, were sufficient to describe the folding kinetics of OmpA.

We therefore first attempted to analyze our kinetic data for FomA folding into $d i \mathrm{C}_{10: 0} \mathrm{PC}$ or $d i \mathrm{C}_{18: 1} \mathrm{PC}$ at molar lipid/FomA ratios of 1000 by fitting either mono-exponential functions assuming single-step first order rate-law or by fitting equation (1) assuming single-step second-order kinetics. The fits were unsatisfactory for describing the folding kinetics of FomA into lipid bilayers (Figure 5, dotted fit lines) and obviously, the kinetics were more complex than

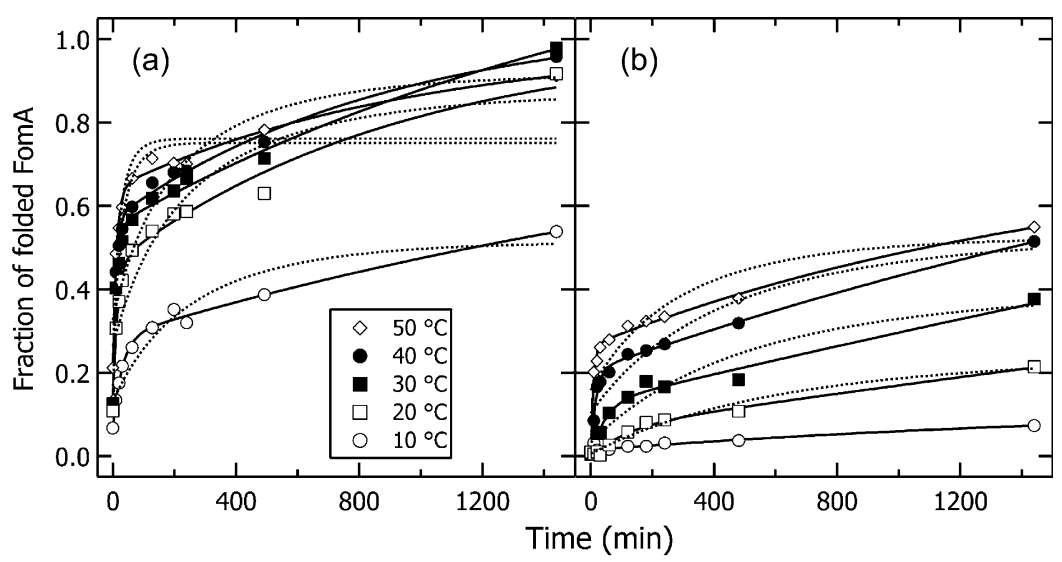

Figure 5. The fractions of folded FomA in $d_{i C_{10: 0}} \mathrm{PC}(\mathrm{a})$ and $d i \mathrm{C}_{18: 1} \mathrm{PC}(\mathrm{b})$, obtained from the gels shown in Figure 4 are plotted as a function of incubation time for folding experiments performed with the two lipids at temperatures between $10^{\circ} \mathrm{C}$ and $50^{\circ} \mathrm{C}$. All kinetics were fitted to double exponential functions (-). Alternatively, data for FomA insertion and folding into $d i \mathrm{C}_{18: 1} \mathrm{PC}$ at 30 and at $40{ }^{\circ} \mathrm{C}$ were also fitted to a second-order rate law (equation (1)), assuming a single insertion and folding step $(\cdots) .{ }^{15}$ 
Table 2. Rate constants for insertion and folding of FomA into $d i \mathrm{C}_{10: 0} \mathrm{PC}$ and into $d i \mathrm{C}_{18: 1} \mathrm{PC}$ bilayers

\begin{tabular}{|c|c|c|c|c|c|c|c|c|}
\hline $\begin{array}{l}T^{\mathrm{a}} \\
\left({ }^{\circ} \mathrm{C}\right)\end{array}$ & $\begin{array}{c}{[P]^{\mathrm{b}}} \\
\mu \mathrm{m}\end{array}$ & $\begin{array}{l}{[L]^{\mathrm{c}}} \\
(\mathrm{mM})\end{array}$ & $A_{\mathrm{F}}^{\mathrm{d}}$ & $\begin{array}{c}k_{\mathrm{F}}^{\mathrm{e}} \\
\left(\mathrm{min}^{-1}\right)\end{array}$ & $\begin{array}{c}k_{\mathrm{f}, 2 \text { ord }}{ }^{\mathrm{f}} \\
\left(\min ^{-1} \cdot \mathrm{M}^{-1}\right)\end{array}$ & $A_{\mathrm{S}}^{\mathrm{d}}$ & $\begin{array}{c}k_{\mathrm{S}}^{\mathrm{e}} \\
\left(\mathrm{min}^{-1}\right)\end{array}$ & $\begin{array}{c}k_{\mathrm{S}, 2 \text { ord }} \mathrm{f}^{-1} \\
\left(\min ^{-1} \cdot \mathrm{M}^{-1}\right)\end{array}$ \\
\hline \multicolumn{9}{|c|}{ A. Fom $A$ insertion and folding into di $\mathrm{C}_{10: 0} \mathrm{PC}$ bilayers } \\
\hline 50 & 7 & 7 & 0.55 & 0.082 & 11.7 & 0.45 & 0.00103 & 0.15 \\
\hline 40 & 7 & 7 & 0.48 & 0.11 & 15.0 & 0.52 & 0.00113 & 0.16 \\
\hline 30 & 7 & 7 & 0.34 & 0.086 & 12.3 & 0.66 & 0.00053 & 0.075 \\
\hline 20 & 7 & 7 & 0.27 & 0.058 & 8.3 & 0.73 & 0.00038 & 0.054 \\
\hline 10 & 7 & 7 & 0.26 & 0.032 & 4.6 & 0.74 & 0.00037 & 0.052 \\
\hline \multicolumn{9}{|c|}{ B. Fom $A$ insertion and folding into di $\mathrm{C}_{18: 1} \mathrm{PC}$ bilayers } \\
\hline 50 & 7 & 7 & 0.35 & 0.118 & 16.9 & 0.65 & 0.00062 & 0.089 \\
\hline 40 & 7 & 7 & 0.17 & 0.059 & 8.4 & 0.83 & 0.00027 & 0.039 \\
\hline 30 & 7 & 7 & 0.06 & 0.022 & 3.1 & 0.94 & 0.00009 & 0.13 \\
\hline \multicolumn{9}{|c|}{$\begin{array}{l}\text { a Temperature } \\
\text { b Concentration of FomA. } \\
\text { c Concentration of lipid. } \\
\text { d Relative contribution of each of the two kinetic phases (obtained by division of each pre-exponential fit parameter by the sum of the } \\
\text { two pre-exponential fit parameters, see equation (2)). } \\
\text { e Pseudo first-order rate constants determined from double exponential fits to Eq. } 2 \text {. } \\
\text { f Lipid concentration-independent second order rate constants, } 15 \text { determined from the first-order rate constants by division by the } \\
\text { lipid concentration, assuming psuedo-first-order kinetics for each phase. }\end{array}$} \\
\hline
\end{tabular}

those observed in previous studies on OmpA. Our data were fitted well by two first-order kinetic phases, independent of the lipid used in FomA folding experiments. The non-linear least-squares fits of double-exponential functions:

$$
\begin{aligned}
{\left[P_{\mathrm{F}}\right](t)=} & \left(A_{1}+A_{2}\right)\left[A_{0}+A_{\mathrm{F}} \exp \left(k_{\mathrm{F}} t\right)\right. \\
& \left.+A_{\mathrm{S}} \exp \left(k_{\mathrm{S}} t\right)\right]
\end{aligned}
$$

to our data are shown in Figure 5 (continuous fit lines). In equation $(2)\left[P_{F}\right](t)$ is the concentration of the folded protein at time $t, k_{\mathrm{F}}$ and $k_{\mathrm{S}}$ are the rate constants of the fast and the slow kinetic phases and the pre-exponential factors $A_{\mathrm{F}}=A_{1} /\left(A_{1}+A_{2}\right)$ and $A_{\mathrm{S}}=A_{2} /\left(A_{1}+A_{2}\right)$, their relative contributions to the folding kinetics. The relative contributions and the calculated rate constants of the two observed kinetic phases of FomA insertion and folding are summarized in Table 2 for folding into $d_{i \mathrm{C}_{10: 0}} \mathrm{PC}$ (Table $2 \mathrm{~A}$ ) and into $d i \mathrm{C}_{18: 1} \mathrm{PC}$ (Table 2B).

In the case of Fom $A$ folding into $d i \mathrm{C}_{10: 0} \mathrm{PC}$, the rate constant of the fast kinetic phase was about 100 -fold greater than the rate constant of the slow kinetic phase (Table 2A). When folding of FomA was monitored at temperatures above $30{ }^{\circ} \mathrm{C}$, both kinetic phases contributed to about the same extent to the formation of folded FomA. At $30^{\circ} \mathrm{C}$ or below, the slow phase dominated. Both rate constants showed similar temperature dependences.

For FomA folding into $d i \mathrm{C}_{18: 1} \mathrm{PC}$, the rate constant of the fast kinetic phase was about 200-fold greater than the rate constant of the slow kinetic phase (Table 2B). The slow process dominated up to $50{ }^{\circ} \mathrm{C}$. The rate constants of the slow process of FomA folding into diC $_{18: 1} \mathrm{PC}$ were significantly smaller than the rate constants of the slow process of Fom A folding into di $\mathrm{C}_{10: 0} \mathrm{PC}$, when kinetics were monitored at $40^{\circ} \mathrm{C}$ or below, but more similar when monitored at $50{ }^{\circ} \mathrm{C}$. Surprisingly, the rate constants of the faster phases of the two folding reactions in $d i \mathrm{C}_{10: 0} \mathrm{PC}$ and in $d i \mathrm{C}_{18: 1} \mathrm{PC}$ were quite similar above $30{ }^{\circ} \mathrm{C}$ and therefore did not depend much on the thickness of the lipid bilayer. Rate constants for FomA insertion and folding into $\mathrm{diC}_{18: 1} \mathrm{PC}$ at $20^{\circ} \mathrm{C}$ or below could not be determined with sufficient accuracy because folding yields were low.

The relative contribution of the fast folding process $\left(A_{\mathrm{F}}\right)$ to the overall folding rate of FomA increased with temperature, for each of the lipids (Table 2). However, $A_{\mathrm{F}}$ was smaller for $d i \mathrm{C}_{18: 1} \mathrm{PC}$ than for $d i \mathrm{C}_{10: 0} \mathrm{PC}$.

\section{Determination of activation energies}

The strong temperature dependence of the rate constants of insertion and folding of FomA into lipid bilayers (SUV) of $d i \mathrm{C}_{10: 0} \mathrm{PC}$ and of $d i \mathrm{C}_{18: 1} \mathrm{PC}$ were used to estimate the corresponding activation energies from Arrhenius plots (Figure 6). Activation energies for FomA folding into $d i \mathrm{C}_{10: 0} \mathrm{PC}$ were $E_{\mathrm{A}}\left(\right.$ diC $\left._{10: 0} \mathrm{PC}, \mathrm{F}\right) \approx 19 \mathrm{~kJ} / \mathrm{mol}$ for the faster step and $E_{\mathrm{A}}\left(d_{\left.i \mathrm{C}_{10: 0} \mathrm{PC}, S\right)} \approx 24 \mathrm{~kJ} / \mathrm{mol}\right.$ for the slower step (Figure 6(a)). For FomA folding into

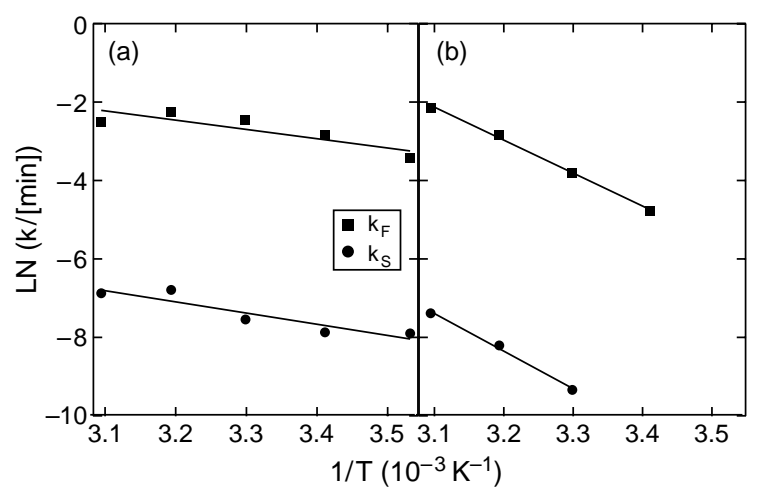

Figure 6. Logarithmic plots of the rate constants of folding versus reciprocal temperature show Arrhenius temperature dependence. Rate constants of the fast $\left(k_{\mathrm{F}}\right)$ and slow $\left(k_{\mathrm{S}}\right)$ phases of FomA folding into $\operatorname{diC}_{10: 0} \mathrm{PC}(\mathrm{a})$ and ${ } \mathrm{C}_{18: 1} \mathrm{PC}(\mathrm{b})$ were determined from double exponential fits to the FomA folding kinetics shown in Figure 5. 
$d i \mathrm{C}_{18: 1} \mathrm{PC}$, activation energies were $E_{\mathrm{A}}\left(d_{i} \mathrm{C}_{18: 1} \mathrm{PC}, \mathrm{F}\right)$ $\approx 69 \mathrm{~kJ} / \mathrm{mol}$ for the fast step and $E_{\mathrm{A}}\left(d_{i C_{18: 1}} \mathrm{PC}, \mathrm{S}\right)$ $\approx 80 \mathrm{~kJ} / \mathrm{mol}$ for the slow step (Figure 6(b)).

\section{Discussion}

In the present detailed study, we have demonstrated that FomA can be used as a first alternative model to OmpA in studies on the biochemical and biophysical mechanisms of membrane insertion and folding of $\beta$-barrel IMPs. This is an important advance, because of three major reasons that will be discussed in separate sections below. First, a second OMP that inserts and folds near quantitatively into lipid bilayers is much needed to clarify whether there are common mechanistic principles of insertion and folding of $\beta$-barrel membrane proteins into lipid membranes. Second, the increased number of $\beta$-strands in the FomA $\beta$-barrel results in a more complex folding process that is composed of two major parallel pathways of structure formation. Third, FomA in combination with OmpA allows folding studies to determine the effect of the size of the $\beta$-barrel transmembrane domain of these proteins on their insertion into lipid bilayers.

\section{Functional insertion and folding of FomA}

Folding of FomA was successful and quantitative into micelles of either LDAO or lyso-capryl phosphatidylcholine and into bilayers of $d i \mathrm{C}_{10: 0} \mathrm{PC}$. FomA folding into $d i \mathrm{C}_{18: 1} \mathrm{PC}$ reached yields of $50 \%$. However, FomA did not form native structure in aqueous solution in the absence of micelles or bilayers. These results are in agreement with previous studies on OmpA, which demonstrated that formation of the native structure of OmpA requires the presence of a supramolecular assembly of amphiphiles, i.e. a detergent micelle or a lipid bilayer, and does not depend much on the detailed chemical structure of the amphiphile. ${ }^{16}$ Similar to $\mathrm{OmpA},{ }^{15}$ the rates of FomA folding were dependent on the structure of the lipid or detergent. Refolded FomA in LDAO was functionally active with the same single channel conductance of $1.1 \mathrm{nS}$ (at $1 \mathrm{M}$ $\mathrm{KCl}$ ) as FomA isolated in native form from outer membranes. ${ }^{26}$ All experimental data indicated that FomA adopts the same $\beta$-barrel structure, independent of the lipid bilayers or detergent micelles used, which corresponds to previous results on OmpA. $7,8,16,27,28,32,33$ Because of the larger transmembrane $\beta$-barrel domain, FomA is a valuable alternative model to OmpA in studies on membrane protein insertion and folding of $\beta$-barrel IMPs.

\section{Kinetics of FomA folding into phospholipid bilayers indicate parallel folding pathways}

While previous KTSE data obtained for OmpA folding into lipid bilayers were well fitted by single- step kinetics, ${ }^{15}$ the present kinetic data on the folding of FomA into lipid bilayers were well fitted only by double-exponential functions, indicating two folding phases, independent of the lipid (Figure 5). Two folding phases can be either sequential or parallel. However, on the gels (Figure 4), we observed only two bands, at 40 and at $37 \mathrm{kDa}$ in all folding experiments and no structural intermediate. Folding was measured by the relative increase of the folded $37 \mathrm{kDa}$ form as a fraction of the entire protein in both, 37 and $40 \mathrm{kDa}$ bands. Possible sequential folding intermediates migrating at $40 \mathrm{kDa}$ together with unfolded FomA cannot explain the presence of a fast and a slow phase in the observed increases of the fraction of the folded form. Only parallel pathways of FomA folding can explain these observed kinetics analyzed by the change in electrophoretic mobility of FomA.

It was observed previously by Western blot analysis $^{25,26}$ that FomA isolated in native form in cell envelopes of F. nucleatum forms trimers. Western blot analysis of recombinant FomA isolated from outer membranes of $E$. coli in native form indicated the presence of monomers. ${ }^{25,35}$ These studies also showed that FomA trimers do not appear in SDS-polyacrylamide gels, even if the samples are not boiled before electrophoresis. ${ }^{25}$ Possibly FomA trimers are formed, but are not very stable. These trimers would then migrate as folded monomers in cold SDS-PAGE. Since we monitor the increase of the fraction of the entire $37 \mathrm{kDa}$ band of folded FomA monomers, which takes place in a fast and a slow process, we do not resolve a subsequent step of trimer formation in our experiments. Therefore, our conclusion about the presence of parallel folding pathways is not affected, even if FomA or a part of FomA would trimerize in a subsequent folding step.

An explanation for the two parallel pathways observed here could be that after urea dilution, a population of unfolded FomA is present within a critical proximity to a vesicle for rapid surface adsorption, while another population of FomA will form a hydrophobically collapsed state in solution, prior to adsorption to the bilayer surface. We observed that FomA develops secondary structure after urea dilution in the absence of lipid or detergent (Table 1). This secondary structure also contained significant content of $\alpha$-helix. For insertion and $\beta$-barrel formation, a larger conformational change is required for such an aqueous intermediate than for FomA that immediately adsorbs to the membrane surface and does not fold into an intermediate with partial helical structure. Conformational changes required for insertion would therefore be larger for the hydrophobically collapsed form, resulting in slower insertion kinetics.

It may also be, that the two populations are distinguished by their orientation in absorbed form on the surface of the lipid bilayer. Reorientation for bilayer insertion may be slower for one of these populations. 
While sequential folding intermediates of OMPs like FomA are probably formed, it is unlikely that these intermediates would be stable enough to resist the interaction with SDS and the electrical field applied in electrophoresis. Only some natively structured OMPs with a well-established and strong hydrogen bonding pattern of the $\beta$-barrel resist unfolding in SDS and electrophoresis conditions. There are also exceptions, such as the nucleoside-specific porin Tsx, which even in native form is not stable enough against unfolding by SDS at room temperature. ${ }^{36}$ The KTSE method therefore resolves only single or parallel folding-steps that lead to a stably folded $\beta$-barrel structure. Single rate constants are obtained for each of the parallel folding routes. The KTSE method will not resolve sequential folding intermediates unless these intermediates migrate differently than the unfolded and native folded forms of the OMP.

\section{Contribution of fast and slow folding pathways to observed folding rates}

The rate constant $k$ of the pseudo-first-order kinetics of FomA folding is directly related to the halftime of folding, $\tau_{1 / 2}=\ln (2) / k{ }^{37}$ Halftimes for Fom $\mathrm{A}$ folding into $d i \mathrm{C}_{10: 0} \mathrm{PC}$ ranged from $\sim 22 \mathrm{~min}$ (at $10{ }^{\circ} \mathrm{C}$ ) to $\sim 7 \mathrm{~min}\left(\right.$ at $40-50{ }^{\circ} \mathrm{C}$ ) for the fast folding pathway and from $\sim 1900 \mathrm{~min}\left(10^{\circ} \mathrm{C}\right)$ to $\sim 700 \mathrm{~min}$ $\left(50^{\circ} \mathrm{C}\right)$ for the slow folding pathway. Similarly, folding of FomA into diC $\mathrm{C}_{18: 1} \mathrm{PC}$ was characterized by halftimes ranging from $\sim 30 \mathrm{~min}$ (at $10^{\circ} \mathrm{C}$ ) to $\sim 6$ min (at 40 to $50{ }^{\circ} \mathrm{C}$ ) for the fast folding pathway and from $\sim 7800 \mathrm{~min}\left(10{ }^{\circ} \mathrm{C}\right)$ to $\sim 1100 \mathrm{~min}$ (at 40 to $50{ }^{\circ} \mathrm{C}$ ) for the slow pathway. Although the slow pathway of FomA folding may not be relevant for the integration of FomA into the outer membrane of a bacterium, our observation is important for two reasons. First, in the analysis of the rate of OMP insertion and folding into lipid bilayers, the rate of the faster process would be underestimated, if kinetic data were analyzed assuming only one folding pathway. In the present study, the relative contribution of the slow pathway depended on the lipid bilayer and on temperature and was in between $45 \%$ and $94 \%$ (Table 2), strongly changing the total folding rate. Second, the knowledge of the existence of the two pathways is important to study the effects of molecular chaperones on the folding of OMPs in model systems. It may well be that periplasmic chaperones such as Skp or SurA or other folding machinery are instrumental in reducing the relative contribution of the slow process. We have recently shown that Skp in combination with LPS can facilitate folding of OmpA into lipid bilayers. ${ }^{20}$ Using FomA as model, it will be interesting to investigate, whether periplasmic chaperones like $\mathrm{Skp}$ can actually reduce the contribution of the slow process to the total folding rate of FomA.

Since rate constants of pseudo first-order reactions depend on lipid concentrations, we estimated the concentration of the outer membrane lipids in cells to approximate the corresponding rate constants and halftimes in vivo. This concentration is at least $\sim 20 \mathrm{mM}$ as calculated from the periplasmic volume, which is about $30 \%{ }^{38}$ of the total cell volume $\left(1.6 \times 10^{-18} \mathrm{~m}^{3}\right)$, the cell surface $\left(7.85 \times 10^{-12} \mathrm{~m}^{2}\right)$, and the lipid-headgroup area (assumed to be $\sim 65 \AA^{2}$; see e.g. Marsh ${ }^{39}$ ), assuming that about half of the inner surface of the outer membrane is covered by lipid, while the other half is covered by protein. The concentration of the lipids available for insertion and folding in cells is therefore $\sim$ fourfold higher than in this in vitro study, which should result in $\sim$ fourfold shorter halftimes. The rates for the faster folding pathways that we observed here are therefore very reasonable.

\section{Folding rates of FomA and OmpA in comparison}

In previous work, the folding of OmpA into bilayers of short-chain phospholipids was very well described by single-step kinetics. ${ }^{15}$ The halftime for OmpA folding into $d i \mathrm{C}_{10: 0} \mathrm{PC}(7 \mathrm{mM})$ was $\sim 2 \mathrm{~min}$ at $20{ }^{\circ} \mathrm{C}$. The folding of FomA into $d i \mathrm{C}_{10: 0} \mathrm{PC}$ had a halftime of $12 \mathrm{~min}$ at $20^{\circ} \mathrm{C}$ for the faster folding phase (Table 2) at a lipid concentration of $7 \mathrm{mM}$, i.e. FomA folding was about six times slower than OmpA folding into this lipid.

However, since OmpA folding was much slower with the phospholipid $d_{i C_{18: 1}} \mathrm{PC}$, we reanalyzed these previously published data ${ }^{13}$ (Figure 7). The new assumption of two parallel kinetic pathways for OmpA folding into these membranes describes the data somewhat better than the assumption of single-phase kinetics,

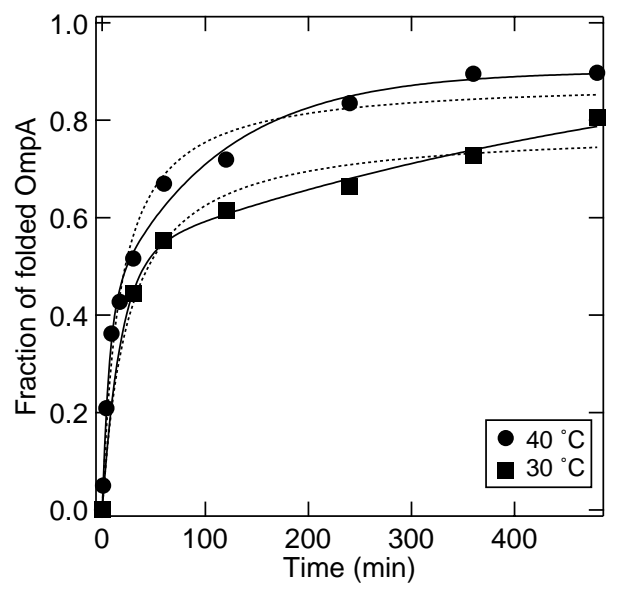

Figure 7. The fraction of the folded $30 \mathrm{kDa}$ form of OmpA in lipid bilayers $d i \mathrm{C}_{18: 1} \mathrm{PC}$ is plotted as a function of time after initiation of the folding reaction. The timecourses of two refolding experiments performed at 30 and at $40{ }^{\circ} \mathrm{C}$ are shown. The concentrations of OmpA and $\operatorname{diC}_{18: 1} \mathrm{PC}$ were $9 \mu \mathrm{M}$ and $3.4 \mathrm{mM}$, respectively. The data were taken from Kleinschmidt \& Tamm ${ }^{13}$ and fitted to a double-exponential function (-), equation (2), or to single-step second-order kinetics, equation (1) $(\cdots)$, as described. ${ }^{15}$ 
although the differences between the two fits are not as pronounced as for the folding of FomA and may be also only statistical deviation of the data from single-step second-order kinetics. The rate constants for the fast and slow processes of OmpA folding at $40{ }^{\circ} \mathrm{C}$ were calculated from the fits shown in Figure 7 and were $0.15 \mathrm{~min}^{-1}\left(A_{\mathrm{F}}=\right.$ $0.46)$ and $0.01 \mathrm{~min}^{-1}\left(A_{\mathrm{S}}=0.54\right)$, corresponding to halftimes of $5 \mathrm{~min}$ and $76 \mathrm{~min}$, respectively, at a lipid concentration of $3.6 \mathrm{mM}$. Halftimes of FomA folding at $7 \mathrm{mM} \mathrm{diC}_{18: 1} \mathrm{PC}$, but under otherwise very similar conditions, were $12 \mathrm{~min}$ for the fast and 2600 min for the slow phase of FomA folding (Table 2). Taking into account the approximate twofold higher lipid concentration used here, the faster phase of FomA folding into $d_{i} C_{18: 1} P C$ is about five times slower than the faster phase of OmpA folding into this lipid.

In conclusion, we found that the fast folding pathway is about five to six times slower for FomA than folding of OmpA at the same lipid concentration for both lipid species, which is likely caused by the increased size of the transmembrane domain of FomA compared to OmpA.

\section{Chain length dependence of insertion and folding of FomA into lipid bilayers}

Folding kinetics of FomA into $d i \mathrm{C}_{18: 1} \mathrm{PC}$ were slower than into $d i \mathrm{C}_{10: 0} \mathrm{PC}$ (Table 2), because the relative contribution of the slow phase was greater for the longer chain phospholipid. In addition, the rate of the slow phase decreased more strongly with increased chain-length of the phospholipid than the rate of the faster phase.

A likely explanation for the faster rate of folding into $d i \mathrm{C}_{10: 0} \mathrm{PC}$ bilayers could be that the thinner bilayers are more flexible, ${ }^{40}$ supporting changes in protein orientation relative to the bilayer surface and therefore increasing the likelihood for insertion. It is possible that on a less flexible bilayer, a smaller fraction of the inserting FomA molecules would have the right orientation for insertion and folding along the fast pathway (Table 2). This interpretation would also be consistent with the temperature dependence of the relative contribution of the faster folding pathway, which is increased at higher temperatures, i.e. at higher flexibility of the bilayer. The rate constant of the faster process is not quite as strongly affected by bilayer thickness as the relative contribution of the fast folding process to the total rate of folding (Table 2).

A second explanation may also be that folding into $d i \mathrm{C}_{18: 1} \mathrm{PC}$ could be slower because the hydrophobic thickness of this bilayer may be greater than the length of the hydrophobic transmembrane domain of OMPs, which is in the range of 22-25 $\AA$, i.e. shorter than the hydrophobic length of $\alpha$-helix bundle IMPs. In folding studies, fluid $d i \mathrm{C}_{10: 0} \mathrm{PC}$ bilayers may provide a better hydrophobic matching to OMPs than fluid $d i \mathrm{C}_{18: 1} \mathrm{PC}$, because the chains of $d i \mathrm{C}_{10: 0} \mathrm{PC}$ may be stretched in the vicinity of IMPs with longer hydrophobic length ${ }^{41}$ (reviews ${ }^{42,43}$ ). The energy requirement for bilayer thickening is small up to the limit of full extension of the acyl chains. The energy cost of a $33 \%$ increase in bilayer thickness, which corresponds to a $\sim 25 \%$ reduction of the molecular surface area, is only about $2 k_{\mathrm{B}} T$ per molecule. ${ }^{44,45}$ $\mathrm{DiC}_{18: 1} \mathrm{PC}$, which has a hydrophobic thickness of $27( \pm 1) \AA,{ }^{46}$ would have to be compressed to match the hydrophobic thickness of OMPs. Membrane thinning may not occur as readily as membrane thickening, because even $2-3 \%$ surface area increases destabilize the bilayer structure and break membranes. ${ }^{47}$

FomA may remain well dispersed in lipid bilayers of different thickness. Lewis \& Engelman demonstrated in a previous study that BR (with a hydrophobic thickness of $\sim 30 \AA)^{48}$ remains well dispersed in bilayers with hydrophobic thicknesses ranging from $19.5 \AA$ to $34 \AA{ }^{46}$ In their study, BR aggregation occurred in thick bilayers when the mismatch exceeded $6 \AA$. However, in thin bilayers a mismatch of up to $14 \AA$ was tolerated.

\section{Perspectives}

Folding of FomA into model membranes worked best at $\mathrm{pH} 10$, above $\mathrm{pI}$ 8.9. Lower yields were obtained at pH 7 (not shown). This is a consequence of the improved solubility of FomA and other OMPs in highly charged form at basic or acidic $\mathrm{pH}^{8,15}$ In vivo, solubility of OMPs in the bacterial periplasm is conferred by complex formation with periplasmic chaperones, such as Skp. ${ }^{20}$ While folding of FomA into lipid bilayers did not require the presence of molecular chaperones or proteinaceous insertion machinery, it is quite likely that certain OMPs such as the recently discovered complex containing YaeT (Omp85), are involved to target OMPs to the outer membrane and are involved to bring OMPs into proper orientation for insertion. Here, we have demonstrated that FomA of F. nucleatum is an important new model to study insertion and folding of OMPs into lipid membranes. It will be interesting to compare the effects of lipid bilayer composition, of periplasmic chaperones such as Skp, or of possible other folding assistants on the relative contributions of the slow and fast phases of FomA folding in future studies. FomA will be a very useful model protein for such studies, since the relative contributions of efficient and non-efficient folding pathways seem well distinguishable with the relatively simple kinetic analysis used here.

\section{Materials and Methods}

\section{Isolation of FomA}

To express FomA in cytoplasmic inclusion bodies in E. coli, fom $A$ was cloned into the expression vector $\mathrm{pET}$ 11c (Stratagene) containing the T7 promoter. The fom $A$ 
gene was amplified by the polymerase chain reaction (PCR) ${ }^{49}$ using plasmid $\mathrm{pHB} 14^{50}$ as a template and as primers $5^{\prime}$-AcatatgGAAGTTATGCCTGCACC- $3^{\prime}$ and 5'-CCTTAGCagatctAGATTAGAAAGTAACTTTC-3 ${ }^{\prime}$ with NdeI and BglII restriction enzyme cut sites (lower case characters). The $5^{\prime}$ primer was designed to replace the codon for the first residue of FomA with a start codon (underlined). The $1073 \mathrm{bp}$ PCR product was cloned into the pCR2.1-TOPO vector (Invitrogen) as described by the manufacturer. Colonies harbouring fom $A$ were identified by PCR using the cloning primers. The DNA fragment carrying fom $A$ was excised with NdeI and BglII and fom $A$ was ligated into the pET-11c vector linearised with NdeI and BamHI. ${ }^{49}$ The resulting plasmid pET-10953 that carries the gene for ampicillin resistance was verified by sequencing.

FomA was expressed in form of cytoplasmic inclusion bodies in E. coli B strain PC2889 harbouring the plasmid pET-10953 as described. ${ }^{51}$ In short: to express FomA, $0.1 \mathrm{M}$ IPTG was added to a PC2889 culture at an $A_{660}$ of 0.6. After $2-3 \mathrm{~h}$, cells were harvested at $4{ }^{\circ} \mathrm{C}$ by centrifugation at $5000 \mathrm{~g}$ for $25 \mathrm{~min}$ and resuspended in buffer (10 mM Tris-HCl (pH 8.0), $5 \mathrm{mM}$ EDTA, 0.1 M $\mathrm{NaCl}$ ). Solutions of $0.8 \mathrm{mg}$ lysozyme and $4 \mathrm{mg}$ of sodium deoxycholate per $1 \mathrm{~g}$ of cells were added and cells were subsequently disrupted using a French pressure cell. The insoluble inclusion bodies of FomA were obtained by centrifugation at $3000 \mathrm{~g}$ for $15 \mathrm{~min}$ at $4{ }^{\circ} \mathrm{C}$ and resuspended in $10 \mathrm{ml}$ of borate buffer $(10 \mathrm{mM}$ borate (pH 10.0), 2 mM EDTA, $10 \mathrm{M}$ urea). FomA was found to be pure $(>99 \%)$ by SDS-PAGE. FomA concentrations of stock solutions were determined using the method of Lowry et al. ${ }^{52}$

\section{Preparation of small and large unilamellar vesicles}

Phospholipids (Avanti Polar Lipids, Alabaster, AL) were dissolved in chloroform, dried under a stream of nitrogen and in a desiccator under high vacuum to prepare thin lipid films. Lipid films were hydrated $(10 \mathrm{mg} / \mathrm{ml})$ in $10 \mathrm{mM}$ borate buffer $(\mathrm{pH} 10)$, with $2 \mathrm{mM}$ EDTA and dispersed by vortexing. SUVs were prepared by $50 \mathrm{~min}$ of sonication using the microtip of a Branson W450D ultrasonifier at $50 \%$ pulse cycle in an ice/water bath. Titanium dust was removed by centrifugation. SUVs were equilibrated overnight at $4{ }^{\circ} \mathrm{C}$ and used on the day after preparation. ${ }^{13}$ LUVs were prepared by seven cycles of freeze-thawing the hydrated lipids in liquid nitrogen and in a water bath at $35{ }^{\circ} \mathrm{C}$. Lipid dispersions were then extruded 30 times through a pair of $100 \mathrm{~nm}$ pore size polycarbonate membranes (Nucleopore, Whatman, Clifton, NJ) using a mini-extruder (Avanti, Alabaster, AL). ${ }^{15}$

\section{Refolding of FomA and trypsin digestion experiments}

Folding of FomA was initiated by rapidly mixing denatured FomA $(10 \mathrm{mg} / \mathrm{ml}$ in $10 \mathrm{M}$ urea) into a 14 times larger volume of $10 \mathrm{mM}$ borate buffer $(\mathrm{pH} 10.0)$ with $2 \mathrm{mM}$ EDTA, containing detergent micelles or lipid vesicles. The molar ratio of lipid or detergent to protein was $1000.20 \mathrm{mg}$ of refolded, functionally active FomA in LDAO detergent or $d i \mathrm{C}_{10: 0} \mathrm{PC}$ bilayers could be obtained from 11 of cell culture, which compares to $2 \mathrm{mg}$ of native FomA isolated from cell membranes from 11 of culture.

For trypsin digestion experiments, $200 \mu \mathrm{l}$ of FomA samples $(0.7 \mathrm{mg} / \mathrm{ml})$ were incubated with $12 \mu \mathrm{l}$ trypsin solution $(1 \mathrm{mg} / \mathrm{ml})$ at $40^{\circ} \mathrm{C}$ for $2 \mathrm{~h}$. Digestion was stopped by addition of $12 \mu \mathrm{l}$ of trypsin inhibitor (1 mg/ml), type I-S from soybean (Sigma).

\section{SDS-polyacrylamide gel electrophoresis}

SDS-polyacrylamide gel electrophoresis (SDS-PAGE) ( $12 \%$ acrylamide) was performed as described, ${ }^{53,54}$ but without heat denaturation of the samples. No high molecular mass aggregates were detected at $\mathrm{pH} \mathrm{10,} \mathrm{in}$ agreement with previous observations on OmpA. ${ }^{8}$

\section{Kinetics of tertiary structure formation detected by electrophoresis (KTSE)}

The KTSE was determined as described for OmpA. ${ }^{13,15,20,21}$ In short: folding of FomA was initiated by rapidly mixing $10 \mu \mathrm{l}$ of denatured FomA $(10 \mathrm{mg} / \mathrm{ml}$ in $10 \mathrm{M}$ urea) with $290 \mu \mathrm{l}$ of $10 \mathrm{mM}$ borate buffer ( $\mathrm{pH}$ 10.0) with $2 \mathrm{mM}$ EDTA, containing lipid vesicles of either $d i \mathrm{C}_{10: 0} \mathrm{PC}$ or $d i \mathrm{C}_{18: 1} \mathrm{PC}$ vesicles. The molar lipid/protein ratio was 1000. The final FomA concentration was $8 \mu \mathrm{M}$. Samples of the reaction mixture were taken at different times after the initiation of folding and added to an equal volume of $0.125 \mathrm{M}$ Tris buffer ( $\mathrm{pH}$ 6.8), containing $4 \%(\mathrm{w} / \mathrm{v})$ SDS, $20 \%(\mathrm{v} / \mathrm{v})$ glycerol, $10 \%(\mathrm{v} / \mathrm{v})$ 2-mercaptoethanol and $0.01 \%(\mathrm{w} / \mathrm{v})$ bromophenol blue. SDS binds to both folded and unfolded FomA and inhibits further folding, similarly as described for OmpA.,13 Timecourses of folding were monitored over $24 \mathrm{~h}$ and analyzed by SDS-PAGE and densitometry.

\section{Folding monitored by CD spectroscopy}

Far UV CD spectra of FomA $(14 \mu \mathrm{M})$ were recorded on a Jasco 715 CD spectropolarimeter using a $0.1 \mathrm{~mm}$ cuvette. Twelve scans were accumulated and averaged from $190 \mathrm{~nm}$ to $250 \mathrm{~nm}(205-250 \mathrm{~nm}$ in the presence of $10 \mathrm{M}$ urea) with a response time of $16 \mathrm{~s}$, a bandwidth of $1 \mathrm{~nm}$, and a scan speed of $20 \mathrm{~nm} / \mathrm{min}$. Background spectra without FomA were subtracted. The recorded $\mathrm{CD}$ spectra were normalized to the mean residue molar ellipticity $[\Theta](\lambda)$, given by:

$$
[\Theta](\lambda)=100 \frac{\Theta(\lambda)}{c \cdot n \cdot l}
$$

where $l$ is the path length of the cuvette in $\mathrm{cm}, \Theta(\lambda)$ is the recorded ellipticity in degrees at wavelength $\lambda, c$ is the concentration in mol/l, and $n$ the number of amino acid residues of FomA. Several deconvolution programs (CONTIN, ${ }^{5,56}$ SELCON3, ${ }^{57}$ and CDSSTR ${ }^{58,59}$ ) were used to analyze the CD spectra. In the case of refolded FomA in lipid or detergent, only the CONTIN algorithm yielded the composition of the secondary structure. This is not surprising, since it is well known that analysis of CD spectra of proteins rich in $\beta$-sheet structure by deconvolution methods is often difficult. ${ }^{60}$

\section{Fluorescence spectroscopy}

Fluorescence spectra of FomA $(0.7 \mu \mathrm{M})$ were recorded at room temperature as described ${ }^{20}$ on a Spex Fluorolog-3 spectrofluorometer with double monochromators in the excitation and emission pathways. The excitation wavelength was $290 \mathrm{~nm}$, and the bandwidths of the excitation monochromators were $2 \mathrm{~nm}$. The bandwidths of the emission monochromators were $3.7 \mathrm{~nm}$. The integration 
time was $0.05 \mathrm{~s}$, and an increment of $0.5 \mathrm{~nm}$ was used to scan spectra in the range of $300-380 \mathrm{~nm}$. Three scans were averaged for each spectrum.

\section{Single-channel conductance experiments}

Planar lipid bilayers were formed from a solution of $1 \%$ diphytanoylphosphatidylcholine (diPhPC) in n-decane using the method described by Mueller et al. ${ }^{61}$ with the modifications described by Busath \& Szabo. ${ }^{62}$ The lipid solution was painted on a $500 \mu \mathrm{m}$ hole in a Teflon partition separating two $6 \mathrm{ml}$ compartments, which were filled with Mes buffer (10 mM Mes, $\mathrm{pH}$ 6.0) containing $1 \mathrm{M} \mathrm{KCl}$. The compartments were connected to the recording system through two AgCl-coated silver electrodes, one of which (the front, cis side) was grounded, whereas the other (the rear, trans side) was connected to a custom designed trans-impedance amplifier. The painted diPhPC/n-decane bilayer membranes were tested for integrity by checking the reflectance optically and also by their resistance and capacitance. After the bilayers were formed, $10 \mu \mathrm{l}$ of refolded FomA $(3 \mu \mathrm{g} / \mathrm{ml})$ in LDAO micelles at an LDAO/FomA ratio of $800 \mathrm{~mol} / \mathrm{mol}$ were added to the cis compartment. The final FomA concentration was $240 \mathrm{pM}$. A potential of $20 \mathrm{mV}$ was applied to the trans compartment. The frequency bandwidth was $100 \mathrm{~Hz}$. Single-channel conductance events were recorded with the IGOR NIDAQ Tools extensions and analyzed using the software IGOR (Wavemetrics, Portland, OR).

\section{Acknowledgements}

This work was supported by grant KL1024/2-6 to J.H.K. and by TP B3 from the Deutsche Forschungsgemeinschaft (DFG) to J.H.K. within the Sonderforschungsbereich TR-SFB 11 of the DFG at the University of Konstanz.

\section{References}

1. Schulz, G. E. (2002). The structure of bacterial outer membrane proteins. Biochim. Biophys. Acta, 1565, 308-317.

2. Kleinschmidt, J. H. (2005). Folding and stability of monomeric $\beta$-barrel membrane proteins. In ProteinLipid Interactions: From Membrane Domains to Cellular Networks (Tamm, L. K., ed.), pp. 27-56, Wiley-VCH, Weinheim.

3. Walton, T. A. \& Sousa, M. C. (2004). Crystal structure of $\mathrm{Skp}$, a prefoldin-like chaperone that protects soluble and membrane proteins from aggregation. Mol. Cell. 15, 367-374.

4. Bitto, E. \& McKay, D. B. (2002). Crystallographic structure of SurA, a molecular chaperone that facilitates folding of outer membrane porins. Structure (Camb), 10, 1489-1498.

5. Doerrler, W. T. \& Raetz, C. R. (2005). Loss of outer membrane proteins without inhibition of lipid export in an Escherichia coli YaeT mutant. J. Biol. Chem. 280, 27679276-27679287.
6. Voulhoux, R., Bos, M. P., Geurtsen, J., Mols, M. \& Tommassen, J. (2003). Role of a highly conserved bacterial protein in outer membrane protein assembly. Science, 299, 262-265.

7. Surrey, T. \& Jähnig, F. (1992). Refolding and oriented insertion of a membrane protein into a lipid bilayer. Proc. Natl Acad. Sci. USA, 89, 7457-7461.

8. Surrey, T. \& Jähnig, F. (1995). Kinetics of folding and membrane insertion of a $\beta$-barrel membrane protein. J. Biol. Chem. 270, 28199-28203.

9. Surrey, T., Schmid, A. \& Jähnig, F. (1996). Folding and membrane insertion of the trimeric $\beta$-barrel protein OmpF. Biochemistry, 35, 2283-2288.

10. Buchanan, S. K. (1999). $\beta$-barrel proteins from bacterial outer membranes: structure, function and refolding. Curr. Opin. Struct. Biol. 9, 455-461.

11. Conlan, S. \& Bayley, H. (2003). Folding of a monomeric porin, OmpG, in detergent solution. Biochemistry, 42, 9453-9465.

12. Kleinschmidt, J. H., den Blaauwen, T., Driessen, A. \& Tamm, L. K. (1999). Outer membrane protein A of E. coli inserts and folds into lipid bilayers by a concerted mechanism. Biochemistry, 38, 5006-5016.

13. Kleinschmidt, J. H. \& Tamm, L. K. (1996). Folding intermediates of a $\beta$-barrel membrane protein. Kinetic evidence for a multi-step membrane insertion mechanism. Biochemistry, 35, 12993-13000.

14. Kleinschmidt, J. H. \& Tamm, L. K. (1999). Timeresolved distance determination by tryptophan fluorescence quenching: probing intermediates in membrane protein folding. Biochemistry, 38, 4996-5005.

15. Kleinschmidt, J. H. \& Tamm, L. K. (2002). Secondary and tertiary structure formation of the $\beta$-barrel membrane protein OmpA is synchronized and depends on membrane thickness. J. Mol. Biol. 324, 319-330.

16. Kleinschmidt, J. H., Wiener, M. C. \& Tamm, L. K. (1999). Outer membrane protein A of E. coli folds into detergent micelles, but not in the presence of monomeric detergent. Protein Sci. 8, 2065-2071.

17. Dornmair, K., Kiefer, H. \& Jähnig, F. (1990). Refolding of an integral membrane protein. OmpA of Escherichia coli. J. Biol. Chem. 265, 18907-18911.

18. de Cock, H., Pasveer, M., Tommassen, J. \& Bouveret, E. (2001). Identification of phospholipids as new components that assist in the in vitro trimerization of a bacterial pore protein. Eur. J. Biochem. 268, 865-875.

19. Mogensen, J. E., Tapadar, D., Schmidt, M. A. \& Otzen, D. E. (2005). Barriers to folding of the transmembrane domain of the Escherichia coli autotransporter adhesin involved in diffuse adherence. Biochemistry, 44, 4533-4545.

20. Bulieris, P. V., Behrens, S., Holst, O. \& Kleinschmidt, J.H. (2003). Folding and insertion of the outer membrane protein OmpA is assisted by the chaperone Skp and by lipopolysaccharide. J. Biol. Chem. 278, 9092-9099.

21. Kleinschmidt, J. H. (2003). Membrane protein folding on the example of outer membrane protein $\mathrm{A}$ of Escherichia coli. Cell. Mol. Life Sci. 60, 1547-1558.

22. Arora, A., Abildgaard, F., Bushweller, J. H. \& Tamm, L. K. (2001). Structure of outer membrane protein A transmembrane domain by NMR spectroscopy. Nature Struct. Biol. 8, 334-338.

23. Pautsch, A. \& Schulz, G. E. (2000). High-resolution structure of the OmpA membrane domain. J. Mol. Biol. 298, 273-282. 
24. Kinder, S. A. \& Holt, S. C. (1993). Localization of the Fusobacterium nucleatum T18 adhesin activity mediating coaggregation with Porphyromonas gingivalis T22. J. Bacteriol. 175, 840-850.

25. Puntervoll, P., Ruud, M., Bruseth, L. J., Kleivdal, H., Høgh, B. T., Benz, R. \& Jensen, H. B. (2002). Structural characterization of the fusobacterial non-specific porin FomA suggests a 14-stranded topology, unlike the classical porins. Microbiology, 148, 3395-3403.

26. Kleivdal, H., Benz, R. \& Jensen, H. B. (1995). The Fusobacterium nucleatum major outer-membrane protein (FomA) forms trimeric, water-filled channels in lipid bilayer membranes. Eur. J. Biochem. 233, 310-316.

27. Arora, A., Rinehart, D., Szabo, G. \& Tamm, L. K. (2000). Refolded outer membrane protein A of Escherichia coli forms ion channels with two conductance states in planar lipid bilayers. J. Biol. Chem. 275, 1594-1600.

28. Schweizer, M., Hindennach, I., Garten, W. \& Henning, U. (1978). Major proteins of the Escherichia coli outer cell envelope membrane. Interaction of protein II with lipopolysaccharide. Eur. J. Biochem. 82, 211-217.

29. Locher, K. P. \& Rosenbusch, J. P. (1997). Oligomeric states and siderophore binding of the ligand-gated FhuA protein that forms channels across Escherichia coli outer membranes. Eur. J. Biochem. 247, 770-775.

30. Wimley, W. C. \& White, S. H. (1996). Experimentally determined hydrophobicity scale for proteins at membrane interfaces. Nature Struct. Biol. 3, 842-848.

31. Yau, W. M., Wimley, W. C., Gawrisch, K. \& White, S. H. (1998). The preference of tryptophan for membrane interfaces. Biochemistry, 37, 14713-14718.

32. Vogel, H. \& Jähnig, F. (1986). Models for the structure of outer-membrane proteins of Escherichia coli derived from Raman spectroscopy and prediction methods. J. Mol. Biol. 190, 191-199.

33. Rodionova, N. A., Tatulian, S. A., Surrey, T., Jähnig, F. \& Tamm, L. K. (1995). Characterization of two membranebound forms of OmpA. Biochemistry, 34, 1921-1929.

34. Sugawara, E., Steiert, M., Rouhani, S. \& Nikaido, H. (1996). Secondary structure of the outer membrane proteins OmpA of Escherichia coli and OprF of Pseudomonas aeruginosa. J. Bacteriol. 178, 6067-6069.

35. Kleivdal, H., Puntervoll, P. \& Jensen, H. B. (2001). Topological investigations of the FomA porin from Fusobacterium nucleatum and identification of the constriction loop L6. Microbiology, 147, 1059-1067.

36. Maier, C., Bremer, E., Schmid, A. \& Benz, R. (1988). Poreforming activity of the Tsx protein from the outer membrane of Escherichia coli. Demonstration of a nucleoside-specific binding site. J. Biol. Chem. 263, 2493-2499.

37. Atkins, P. W. (1998). Physical Chemistry. 6th edit., W.H. Freeman and Co., New York.

38. Stock, J. B., Rauch, B. \& Roseman, S. (1977). Periplasmic space in Salmonella typhimurium and Escherichia coli. J. Biol. Chem. 252, 7850-7861.

39. Marsh, D. (1990). CRC Handbook of Phospholipid Bilayers. CRC Press, Boca Raton.

40. Rawicz, W., Olbrich, K. C., McIntosh, T., Needham, D. \& Evans, E. (2000). Effect of chain length and unsaturation on elasticity of lipid bilayers. Biophys. J. 79, 328-339.

41. de Planque, M. R., Greathouse, D. V., Koeppe, R. E., 2nd, Schafer, H., Marsh, D. \& Killian, J. A. (1998).
Influence of lipid/peptide hydrophobic mismatch on the thickness of diacylphosphatidylcholine bilayers. A ${ }^{2} \mathrm{H}-\mathrm{NMR}$ and ESR study using designed transmembrane $\alpha$-helical peptides and gramicidin A. Biochemistry, 37, 9333-9345.

42. Killian, J. A. (1998). Hydrophobic mismatch between proteins and lipids in membranes. Biochim. Biophys. Acta, 1376, 401-415.

43. Marsh, D. (1990). Lipid-protein interactions in membranes. FEBS Letters, 268, 371-375.

44. Lis, L. J., McAlister, M., Fuller, N., Rand, R. P. \& Parsegian, V. A. (1982). Measurement of the lateral compressibility of several phospholipid bilayers. Biophys. J. 37, 667-672.

45. Parsegian, V. A., Fuller, N. \& Rand, R. P. (1979). Measured work of deformation and repulsion of lecithin bilayers. Proc. Natl Acad. Sci. USA, 76, 2750-2754.

46. Lewis, B. A. \& Engelman, D. M. (1983). Lipid bilayer thickness varies linearly with acyl chain length in fluid phosphatidylcholine vesicles. J. Mol. Biol. 166, 211-217.

47. Kwok, R. \& Evans, E. (1981). Thermoelasticity of large lecithin bilayer vesicles. Biophys. J. 35, 637-652.

48. Pebay-Peyroula, E., Rummel, G., Rosenbusch, J. P. \& Landau, E. M. (1997). X-ray structure of bacteriorhodopsin at 2.5 angstroms from microcrystals grown in lipidic cubic phases. Science, 277, 1676-1681.

49. Sambrook, J., Fritsch, E. F. \& Maniatis, T. (1989). Molecular Cloning: A Laboratory Manual. 2nd edit., Cold Spring Harbor Laboratory Press, Cold Spring Harbor, NY.

50. Jensen, H. B., Skeidsvoll, J., Fjellbirkeland, A., Høgh, B., Puntervoll, P., Kleivdal, H. \& Tommassen, J. (1996). Cloning of the fomA gene, encoding the major outer membrane porin of Fusobacterium nucleatum ATCC10953. Microb. Pathog. 21, 331-342.

51. Qi, S. Y., Li, Y. \& O'Connor, C. D. (1994). The region around residue 115 of human bactericidal/ permeability-increasing protein is not involved in lipopolysaccharide binding or bactericidal activity. Chemical synthesis and expression of a gene coding for the active domain and characterization of recombinant proteins. Biochem. J. 298, 711-718.

52. Lowry, O. H., Rosebrough, N. J., Farr, A. L. \& Randall, R. J. (1951). Protein measurement with the folin phenol reagent. J. Biol. Chem. 193, 265-275.

53. Laemmli, U. K. (1970). Cleavage of structural proteins during the assembly of the head of bacteriophage T4. Nature, 227, 680-685.

54. Weber, K. \& Osborne, M. (1964). The reliability of molecular weight determinations by dodecyl sulfatepolyacrylamide gel electrophoresis. J. Biol. Chem. 244, 4406-4412.

55. Provencher, S. W. \& Glockner, J. (1981). Estimation of globular protein secondary structure from circular dichroism. Biochemistry, 20, 33-37.

56. van Stokkum, I. H., Spoelder, H. J., Bloemendal, M., van Grondelle, R. \& Groen, F. C. (1990). Estimation of protein secondary structure and error analysis from circular dichroism spectra. Anal. Biochem. 191, 110-118.

57. Sreerama, N., Venyaminov, S. Y. \& Woody, R. W. (1999). Estimation of the number of alpha-helical and beta-strand segments in proteins using circular dichroism spectroscopy. Protein Sci. 8, 370-380.

58. Compton, L. A. \& Johnson, W. C., Jr (1986). Analysis of protein circular dichroism spectra for secondary structure using a simple matrix multiplication. Anal. Biochem. 155, 155-167. 
59. Sreerama, N. \& Woody, R. W. (2000). Estimation of protein secondary structure from circular dichroism spectra: comparison of CONTIN, SELCON, and CDSSTR methods with an expanded reference set. Anal. Biochem. 287, 252-260.

60. Greenfield, N. J. (1996). Methods to estimate the conformation of proteins and polypeptides from circular dichroism data. Anal. Biochem. 235, $1-10$.
61. Mueller, P., Rudin, D. O., Tien, H. T. \& Wescott, W. C. (1962). Reconstitution of cell membrane structure in vitro and its transformation into an excitable system. Nature, 194, 979-980.

62. Busath, D. \& Szabo, G. (1981). Gramicidin forms multi-state rectifying channels. Nature, 294, 371-373.

63. Whitmore, L. \& Wallace, B. A. (2004). DICHROWEB, an online server for protein secondary structure analyses from circular dichroism spectroscopic data. Nucl. Acids Res. 32, W668-W673. 